\title{
Spatial Characteristics and Driving Forces of Cultivated Land Changes by Coupling Spatial Autocorrelation Model and Spatial-temporal Big Data
}

\author{
Wang Hua $^{1}$, Zhu Yuxin ${ }^{1}$, Wang Mengyu ${ }^{1}$, Niu Jiqiang ${ }^{2}$, Chen Xueye ${ }^{3}$, and Zhang Yang ${ }^{4 *}$ \\ ${ }^{1}$ Henan Key Laboratory of food safety data intelligence, Zhengzhou University of Light Industry \\ Zhengzhou, 450002, China \\ [e-mail: whuwanghua@163.com,ZhuYuxin1010@163.com,2528933224@qq.com] \\ ${ }^{2}$ Key Laboratory for Synergistic Prevention of Water and Soil Environmental Pollution \\ Xinyang Normal University, Xinyang, 464000, China \\ [e-mail: 1090531394@qq.com] \\ ${ }^{3}$ Key Laboratory of Urban Land Resources Monitoring and Simulation, Ministry of Natural Resources \\ Shenzhen, 518034, China \\ [e-mail: 2013016@zzuli.edu.cn] \\ ${ }^{4}$ College of Urban Economics and Public Administration, Capital University of Economics and Business, \\ Beijing, 100070, China \\ [e-mail: geozhangyang@yeah.net] \\ *Corresponding author: Zhang Yang
}

Received December 8, 2020; revised January 13, 2021; accepted January 23, 2021; published February 28, 2021

\begin{abstract}
With the rapid development of information technology, it is now possible to analyze the spatial patterns of cultivated land and its evolution by combining GIS, geostatistical analysis models and spatiotemporal big data for the dynamic monitoring and management of cultivated land resources. The spatial pattern of cultivated land and its evolutionary patterns in Luoyang City, China from 2009 to 2019 were analyzed using spatial autocorrelation and spatial autoregressive models on the basis of GIS technology. It was found that: (1) the area of cultivated land in Luoyang decreased then increased between 2009 and 2019, with an overall increase of $0.43 \%$ in 2019 compared to 2009 , with cultivated land being dominant in the overall landscape of Luoyang; (2) cultivated land holdings in Luoyang are highly spatially autocorrelated, with the 'high-high'-type area being concentrated in the border area directly north and northeast of Luoyang, while the 'low-low'-type area is concentrated in the south and in the municipal area of Luoyang, and being heavily influenced by topography and urbanization. The expansion determined during the study period mainly took place in the Luoyang City, with most of it being transferred from the 'high-low'-type area; (3) elevation, slope and industrial output values from analysis of the bivariate spatial autocorrelation and spatial autoregressive models of the drivers all had significant effects on the amount of cultivated land holdings, with elevation having a positive effect, and slope and industrial output having a negative effect.
\end{abstract}

Keywords: Cultivated Land, Spatial Pattern Evolution, Spatial Autocorrelation, Spatial Autoregression, Spatio-temporal Big Data, Drive Mechanism 


\section{Introduction}

W ith the development of China's new type of urbanization and industrialization, phenomena such as the occupation of cities and towns, internal agricultural restructuring, the ecological restoration of cultivated land to forest and grassland, and destruction by natural disasters have become increasingly prominent, resulting in a continuous reduction in cultivated land resources, a gradual decline in the quality of cultivated land, and a decrease in the ecological functions of cultivated land [1-3]. A serious shortage of reserve cultivated land resources in China has further exacerbated the contradictions between population growth, resource utilization and cultivated land protection, and the problem of how to coordinate these three contradictions has become increasingly prominent, making cultivated land resources an important strategic resource for national food security, ecological and environmental protection, and social stability. Especially since the 18th National Congress of the Communist Party of China(CPC), the CPC Central Committee has attached great importance to the protection of cultivated land, establishing a new pattern of cultivated land protection based on the 'trinity' of quantity, quality and ecology, and building a new mechanism for cultivated land protection that combines control, construction and incentives [4-5].

Due to the frequency and complexity of transfer between cultivated and other land types, changes in cultivated land have been a hot topic in academic studies, with the main research topics including trends and driving mechanisms [6-7], methods of cultivated land conservation and management [8-9], quality assessment, and ecological responses [10-11]. In particular, certain researchers have revealed the spatial and temporal changes in regional cultivated land resources, which are of great significance for promoting the sustainable use of cultivated land and safeguarding food security in China.

Previous studies on the spatial patterns of cultivated land have mainly focused on the temporal and spatial changes in cultivated land [12], the changes in spatial patterns of cultivated land [13], the driving mechanisms of cultivated land changes [14], and the simulation and prediction of cultivated land changes [15]. The topic has gradually transitioned from the macro level of global [16], continental, national, and regional to the meso level of watershed, county and city, with different time spans. Most of these studies are based on independent evaluation units, using traditional mathematical statistical methods [17],geographic statistical methods and spatial analysis [18], all of which have yielded useful results and contributed to the study of the spatial evolution of cultivated land. Most of these studies have dealt with the spatial distribution of cultivated land at the macro level, however, with few studies focusing on the spatial correlation of cultivated land and the dynamically changing spatial pattern of cultivated land. The spatial autocorrelation method is able to reflect the distribution characteristics of spatial variables and their influence on neighborhoods [19]. In recent years, there have been several achievements in the study of the spatial pattern of cultivated land [20-22].

Over many years, scholars at home and abroad have extensively discussed the mechanisms that influence changes in cultivated land in the process of rapid urbanization [2325]. Studies have shown that there is an intrinsic relationship between changes in cultivated land resources and several factors, such as elevation, slope, topography, per-capita gross domestic product, roads, level of comprehensive socioeconomic development (level of economic development, population development, urbanization and industrialization), agricultural science and technology innovation and structure, spatial accessibility, level of transportation development, and cultivated land and ecological protection policies [26]. In terms of the methods used in analyzing the influencing factors of cultivated land conversion, 
previous research has shown a trend from simple to complex, from correlation analysis to mechanistic explanation. Traditional correlation, principal component and factor analyses are gradually being replaced by regression and cluster analyses, while adaptive intelligence methods, such as artificial neural networks, are gradually being used to study the influencing mechanism of cultivated land change. Anselin has argued that almost all spatial data are spatially correlated or spatially dependent [27], but these methods ignore the influences themselves, and the correlations between them and the cultivated land, which contradicts the assumption that the variables in the correlation analysis are independent of each other, such is the classic linear regression model. However, the spatial autoregressive model modifies this problem by including the spatial dependence into the regression equation, which makes up for the defects of the classical metrological method in the statistical analysis of spatial data and is more in line with the actual needs.

To address the shortcomings of current research, this work used Luoyang-a new subcenter city in China-as the study area, from the perspective of spatial clustering and dependency. The study was based on spatiotemporal big data of cultivated land use in Luoyang for the three years 2009, 2014 and 2019. A spatial autocorrelation model was used to analyze the evolution of the spatial pattern of cultivated land at the township scale in Luoyang, and the spatial dependence between cultivated land and influencing factors was selected as an example. Finally, a spatial autoregressive model was chosen to analyze the driving mechanism of the spatial change of cultivated land in Luoyang, in order to provide support for the coordination of urbanization and cultivated land protection in the new era, and the scientific preparation of national land and spatial planning.

\section{Data and Methods}

\subsection{Overview of the Study Area and Data Acquisition}

\subsubsection{Overview of the Study Area}

The chosen study area was Luoyang City, in the western part of Henan Province in Central China. Luoyang City spans the northern and southern banks of the middle and lower reaches of the Yellow River, located at longitude $112^{\circ} 16^{\prime} \sim 112^{\circ} 37^{\prime} \mathrm{E}$ and latitude $34^{\circ} 32^{\prime} \sim 34^{\circ} 45^{\prime} \mathrm{N}$. The total area of the city is $15,230 \mathrm{~km}^{2}$, with cultivated land accounting for $32.18 \%$ of the total area. Luoyang City is in the transition from the second to the third terrain of China, and its terrain structure is diversified. Mountains, hills and plains dominate the its topography of Luoyang, with mountains accounting for $45.51 \%$, hills accounting for $40.73 \%$ and plains accounting for $13.8 \%$. The city of Luoy ang is also rich in water, mineral and tourism resources. The location of Luoyang City is shown in Fig. 1.

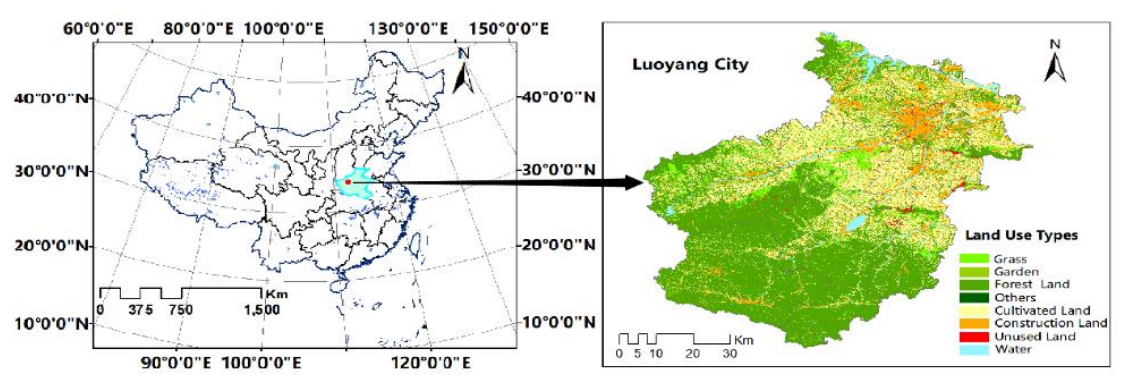

Fig. 1. Location of Luoyang City 


\subsubsection{Data Source and Preprocessing}

The main data for this study were obtained from the Land Survey Change Database for the years 2009, 2014 and 2019. The land classes in the database are based on the second-level standard of the Land Use Status Classification (GB/T 21010-2007) [28]. In order to facilitate analysis, the data needed to be preprocessed, including merging the element classes, filtering out the cultivated land patches and obtaining the base data for the cultivated land patches for the three years under examination(Fig. 2A-C). Following this, the most basic townshipdivision data were merged into the county-level administrative-division data (see Fig. 2D, E). The DEM data came from the Shuttle Radar Topography Mission dataset, provided by the International Scientific Data Service Platform of the Computer Network Information Center, Chinese Academy of Sciences (http://datamirror.csdb.cn). Calculate the average elevation data for each township using the Grid Calculator in the ArcGIS Spatial Analysis module (Fig. 2F). The DEM data were converted to cover the entire area of Luoyang City using the ArcGIS tools, and obtain the average slope data for each township (Fig. 2G). Data on the resident population and industrial output value were obtained from the 2009, 2015 and 2020 editions of the Statistical Yearbook of Luoyang City and the Statistical Yearbook of China's Townships (Fig. $\mathbf{2 H}, \mathbf{I})$. The obtained impact factor data were spatially connected to each township unit in order to obtain the basic analysis layer data.

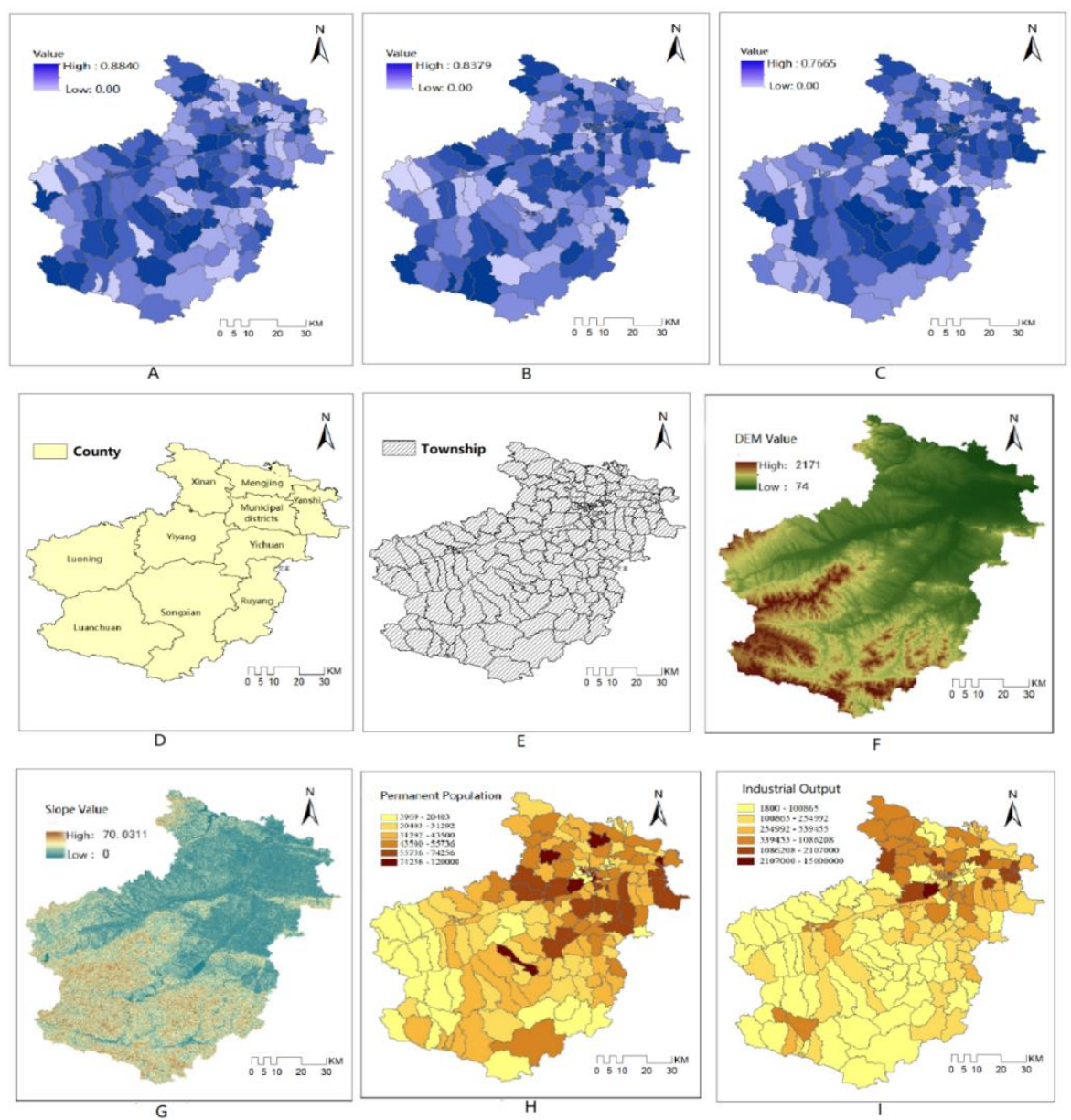

Fig. 2. Partial Temporal and Spatial Data Maps 


\subsection{Research Methodology}

\subsubsection{Land-use Transition Matrix}

The land-use transfer matrix is a mathematical method extended from the quantitative description of the system state and state transfer in system analysis. In the transfer matrix (Table 1), Al-An is the land-use type. Snn represents the transformed area of the two land classes in the corresponding year. $P n+-P+n$ represents the change in area from $P+n$ to $P n+$ for each land use type during T1-T2 [29].

Table 1. Land-use Transfer Matrix

\begin{tabular}{l|c|c|c|c|c|c|c}
\hline \multirow{2}{*}{ Land Use Type } & \multicolumn{5}{c|}{$T_{2}$} & \multirow{2}{*}{ Sum } & Decrease \\
\cline { 3 - 6 } \multicolumn{2}{l|}{} & $A_{1}$ & $A_{2}$ & $\cdots$ & $A_{n}$ & & \\
\hline \multirow{4}{*}{$T_{1}$} & $A_{1}$ & $S_{11}$ & $S_{12}$ & $\cdots$ & $S_{1 n}$ & $P_{1+}$ & $P_{1+}-S_{11}$ \\
& $A_{2}$ & $S_{21}$ & $S_{22}$ & $\cdots$ & $S_{2 n}$ & $P_{2+}$ & $P_{2+}-S_{22}$ \\
& $\vdots$ & $\cdots$ & $\cdots$ & & $\cdots$ & $\vdots$ & $\vdots$ \\
& $A_{n}$ & $S_{n 1}$ & $S_{n 2}$ & $\cdots$ & $S_{n n}$ & $P_{n+}$ & $P_{n+}-S_{n n}$ \\
\hline \multicolumn{2}{l|l}{ Sum } & $P_{+1}$ & $P_{+2}$ & $\cdots$ & $P_{+n}$ & & \\
\multicolumn{2}{l|l}{ Increase } & $P_{+1}-S_{11}$ & $P_{+2}-S_{22}$ & $\cdots$ & $P_{+n}-S_{n n}$ & & \\
\hline
\end{tabular}

From the transfer matrix, the area changes in various land classes can be derived. In this study, we used the Spatial Analyst tool in ArcGIS to process the land-use data of Luoyang City in 2009, 2014 and 2019 in order to obtain the land-use transfer matrix. From the obtained matrix, the area of cultivated land converted to urban construction land, forestland and other land categories became apparent, as well as the area of other land categories converted to cultivated land between 2009 and 2014 and 2014 and 2019. From these results, it was possible to visualize the compensation for the occupation of cultivated land and its dynamics.

\subsubsection{Spatial Autocorrelation Analysis}

Spatial autocorrelation analysis is a method used to check whether observations with spatiallylocated elements correlate with observations at neighboring spatial points. The determination of spatial weight is the basis of spatial correlation analysis. Since the cultivated land is continuously distributed, the Queen adjacency, which considers both the common vertex and the common edge, is chosen in this paper to determine the weight matrix. There are many measures of spatial autocorrelation, with the most common test to quantify this aggregation property being Moran's I. Spatial autocorrelation can be global or local. Moran's I can measure either global or local spatial correlations. Calculation of the global Moran's I is shown in (1).

$$
I=\frac{n \sum_{i=1}^{n} \sum_{j=1}^{n} w_{i j}\left(X_{i}-\bar{X}\right)\left(X_{j}-\bar{X}\right)}{\sum_{i=1}^{n} \sum_{j=1}^{n} w_{i j} \sum_{i=1}^{n}\left(X_{i}-\bar{X}\right)^{2}}
$$


where $n$ is the number of spatially-observed objects in the study area, $X i$ and $X j$ are the values of the $i$-th and $j$-th observations in space, respectively, $\bar{X}$ is the average of all observations of the object, and Wij is the spatial weight matrix that represents the adjacency between the $i$-th and $j$-th observations at a spatial location. Moran's I has a value in the range $[-1,1]$. At a specific significance level, if Moran's I $>0$, there is a spatial positive correlation between the observed objects, which is characterized by the clustering of high or low values of the object's attributes. If Moran's $\mathrm{I}<0$, the opposite is true. If Moran's $\mathrm{I}=0$, this means that the values of the observed objects are randomly distributed and do not have spatial correlation.

Local spatial autocorrelation analysis focuses on the degree of correlation between an attribute value on a regional unit and its neighborhood unit in local space. The calculation formula for local Moran's I is shown in (2), with the meaning of each variable in the equation being the same as that in (1).

$$
I=\frac{\sum_{j=1, j \neq i}^{n} w_{i j}\left(X_{i}-\bar{X}\right)\left(X_{j}-\bar{X}\right)}{\sum_{i=1}^{n}\left(X_{i}-\bar{X}\right)^{2}}
$$

Here, townships were used as the basic unit for calculating the quantity of cultivated land holdings in each township in Luoyang City. The Geoda software platform was then used to analyze the spatial autocorrelation and spatial aggregation characteristics of the cultivated land holdings from both the global and local aspects.

\subsubsection{Spatial autoregression models}

The general form of the spatial regression model is shown in (3).

$$
\begin{aligned}
& \mathrm{Y}=\rho \mathrm{W} 1+\beta \mathrm{X}+\mu \\
& \mu=\lambda \mathrm{W} 2+\varepsilon
\end{aligned}
$$

where $Y$ is the dependent variable, $X$ is the explanatory variable, $\beta$ represents the spatial regression coefficient of the explanatory variables, $\mu$ is the error term, $\varepsilon$ is white noise, spatial weight matrices for $W 1$ and $W 2$ reflecting the spatial trend of the dependent variable and residuals, respectively. $\rho$ is the coefficient of the spatial hysteresis term, $\lambda$ is the coefficient of the spatial error coefficient.

According to the values of $\rho$ and $\lambda$, the spatial regression model can be divided into three sub-models: (1) an ordinary linear regression model is obtained when $\rho=0, \lambda=0$, indicating that the model is not affected by spatial characteristics. This model requires the data in the study area to be independent and evenly distributed; (2) a spatial lag model (SLM) is obtained when $\rho \neq 0, \lambda=0$. The model should be based on spatial autocorrelation; and (3) a spatial error model (SEM) is obtained when $\rho=0, \quad \lambda \neq 0$. The sub-model was evaluated based on indicators such as whether the residual was independent, and whether the Lagrange multiplier (LM) and the robust LM had statistical significance. In fact, research data often have spatial autocorrelation. The spatial autoregressive model (SLM and SEM) incorporated this point into the regression equation, which makes up for the shortcomings of the classical measurement method in the statistics of spatial data. 


\section{Results and Analysis}

\subsection{Cultivated Land Transfer Analysis}

The dynamic change in cultivated land is not only manifested by the increase and decrease in spatial orientation, but also by the mutual transformation with other geotypes. This can be visualized in terms of the decreases and interconversions that have a strong influence on cultivated land, which help to provide an understanding of its evolutionary flow. For this work, the raster data for 2009, 2014 and 2019 were obtained by preliminary processing in ArcGIS, in order to obtain the transfer matrices between cropland and other landscape types for 20092014 and 2014-2019, using the Area Tabulation tool in Spatial Analysis, and shown in Fig. 3 and Fig. 4.

\subsubsection{Analysis of Cultivated Land Transfer Direction from 2009 to 2014}

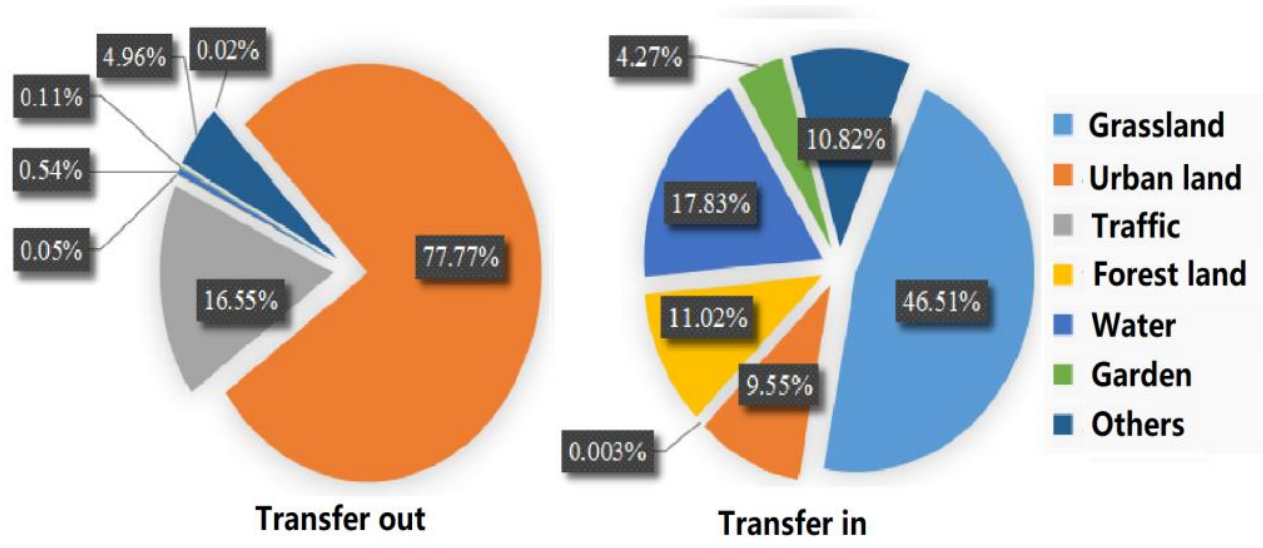

Fig. 3. Transfer Ratio of Cultivated Land in Luoyang City from 2009 to 2014

Total of $10,708.63 \mathrm{hm}^{2}$ of cultivated land was transferred out and $8953.81 \mathrm{hm}^{2}$ was transferred in during the period 2009-2014, meaning a greater amount of cultivated land was transferred out, resulting in an actual decrease of $1754.82 \mathrm{hm}^{2}$ in the cultivated land area.

As can be seen from Fig. 3, the main transfer out of cultivated land was to urban, industrial and mining land, with $8327.58 \mathrm{hm}^{2}$ or $77.77 \%$ of the total, followed by transport land $\left(1771.95 \mathrm{hm}^{2}\right)$ and other land $\left(531.42 \mathrm{hm}^{2}\right)$. Of the cultivated land, $46.51 \%$ came from grassland. Of the cropland, $17.83 \%$ was transferred from water bodies and water facilities, with a significant proportion of the remaining cropland coming from forestland (11.02\%), other land (10.82\%), urban, industrial and mining land (9.55\%) and garden land (4.27\%). The combined transfer of cultivated land into and out of the countryside indicates that the amount of land transferred out of the countryside in 2009-2014 is much greater than the amount of land transferred in, suggesting that urban and industrial development is an important factor in the reduction of cultivated land. 


\subsubsection{Analysis of Cultivated Land Transferdirection from 2014 to 2019}

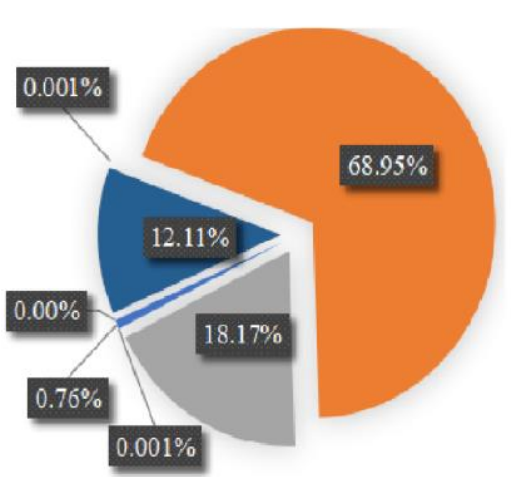

Transfer out

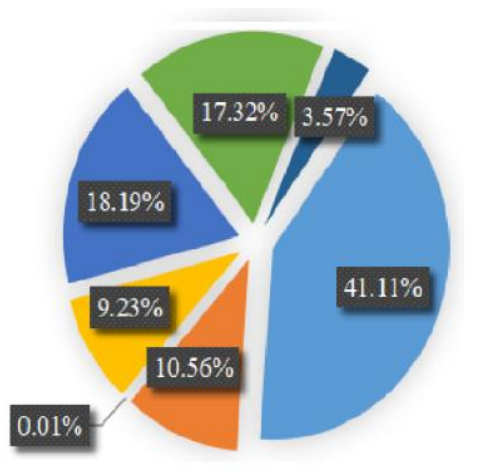

Transfer in

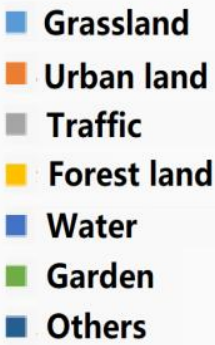

Grassland

Traffic

Forest land

- Water

- Others

Fig. 4. Transfer Ratio of Cultivated Land in Luoyang City from 2009 to 2014

Total amount of cultivated land transferred out of the city of Luoyang in 2014-2019 was $5691.93 \mathrm{hm}^{2}$, while the total amount transferred in was $9549.98 \mathrm{hm}^{2}$, which is a decrease of $46.84 \%$ in the amount transferred out and an increase of $6.66 \%$ in the amount transferred in compared to the previous period, resulting in a net increase of $3858.05 \mathrm{hm}^{2}$ in cultivated land area during this period. As can be seen from Fig. 4, the greatest proportion of cultivated land transferred out of Luoyang City in 2014-2019 continued to be urban, industrial and mining land, accounting for $68.95 \%$ of the total-a decrease of $8.82 \%$ compared to the previous period - with transport land still in second place, accounting for $18.17 \%$, up $1.62 \%$, and other land accounting for $12.11 \%$, a very significant increase compared to the previous period. This is significant, indicating that, in some areas, formerly cultivated land has been converted into unused land, agricultural land for facilities, or unused land, such as sand or bare land. This suggests that there is still much room for improvement in Luoyang City in terms of protecting the quantity and quality of cultivated land.

In terms of the amount of difference in the area of cultivated land transferred into and out of cultivated land, urban, industrial and mining land, transport land and other land are the three major categories of land that have contributed to the decrease in cultivated land, this is due to the development of urbanization, more and more arable land is occupied in the early period. In the later period, it paid more attention to the new development concept and promoted the reform while taking into account the economy, thus reducing the adverse impact on the cultivated land. Grassland, woodland, water and water facilities land and parkland are the sources of the increase in cultivated land, in that order. Compared to 2009-2014, the biggest difference is that other land has been changed from a source of cultivated land transfer to an object of cultivated land transfer, which is a side effect of the fact that land is not used in the most efficient way in urban development and construction, that construction land needs to be planned more rationally, and that land improvement projects should play a greater role.

\subsection{Spatial Autocorrelation Analysis}

\subsubsection{Analysis of the Global Spatial Autocorrelation Results}

In order to study the spatial distribution of cultivated land holdings in Luoyang City, a spatial weight matrix was determined using townships as units and the queen neighborhood approach. 
The global Moran's I values for cultivated land holdings in 2009, 2014 and 2019 were calculated using ArcGIS and Geoda to respectively test the significance of the Moran's index values (Table 2) and to obtain the corresponding Moran's scatter plots (Fig. 5). When carrying out global spatial autocorrelation analysis, it is important to note that, after calculating Moran's $\mathrm{I}$, the level of significance is also checked, often using the $\mathrm{z}$-value and $\mathrm{p}$-value. Most tests begin with a confidence level, which is then judged on the basis of the $\mathrm{z}$-value and $\mathrm{p}$-value of the results of the analyses, commonly using confidence levels of $90 \%, 95 \%$ or $99 \%$.

Table 2. Global Moran's I Values and Test of Cultivated Land Quantity in Luoyang City

\begin{tabular}{|ccccc|}
\hline Year & Moran's I & z-value & p-value & Threshold value $(\boldsymbol{\alpha}=\mathbf{0 . 0 1})$ \\
\hline 2009 & 0.7040 & 14.2589 & 0.0001 & 2.58 \\
\hline 2014 & 0.7133 & 14.3281 & 0.0001 & 2.58 \\
\hline 2019 & 0.7377 & 14.9201 & 0.0001 & 2.58 \\
\hline
\end{tabular}

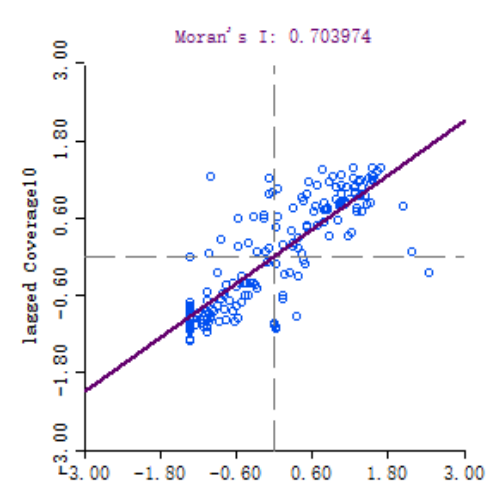

(a) 2009

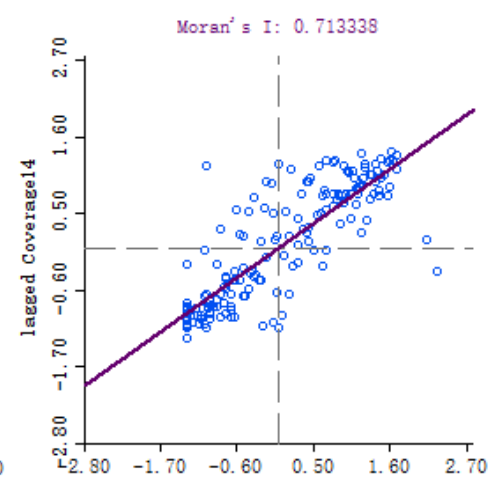

(b) 2014

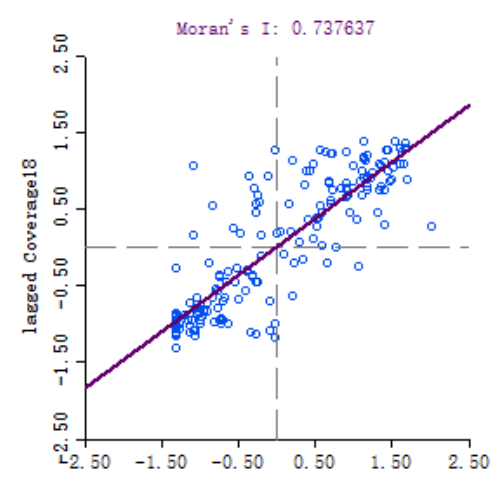

(c) 2019

Fig. 5. Cultivated Land Quantity Moran Scatter Plot in Luoyang City

It can be seen from Fig. 5 that the Moran's I of cultivated land holdings in Luoyang in 2009, 2014 and 2019 are $0.7040,0.7133$ and 0.7376, respectively, with the z-values all greater than the critical value of 2.58, which passes the significance test of $\alpha=0.01$, indicating the spatial existence of cultivated land holdings in Luoyang City. The correlation and three years' of values of the Moran index are all greater than 0.5, indicating that cultivated land holdings at the township scale in Luoyang City are spatially significantly correlated, showing clustering of high or low values. 
From the magnitude of the Moran's I values, Moran's I(2019)>Moran's I(2014)>Moran's $\mathrm{I}(2009)$, indicating that, at a 95\% confidence level, the cultivated land in Luoyang is the degree of spatial correlation of the holdings has increased year on year, indicating an increasingly strong clustering of high or low values of cultivated land holdings in various townships in Luoyang City, with the 2019 cultivated land holdings (Moran's I $\approx 0.7377$ ) showing the strongest positive spatial correlation in recent years.

\subsubsection{Analysis of the Local Spatial Autocorrelation Results}

Local spatial autocorrelation analysis is concerned with the spatial correlation between specific units and their neighboring units, which can effectively reflect the spatial differences caused by spatial autocorrelation between different townships. In order to further study the spatial clustering areas and characteristics of cultivated land holdings in Luoyang City, a local spatial autocorrelation analysis of cultivated land holdings in 2009, 2014 and 2019 was conducted, with the township as the unit. This provided the LISA clustering diagram shown in Fig. 6, which indicates the spatial differentiation in the distribution of cultivated land holdings more visually. 'Low-low' means that the areas with low cultivated land holdings are surrounded by towns with similarly low holdings. 'Low-high' and 'high-low' suggest a negative correlation in the spatial distribution of cultivated land holdings, with low-high meaning that towns with low cultivated land holdings are surrounded by towns with higher holdings, and high-low meaning the opposite. 'Not significant' means that the spatial correlation is not significant.
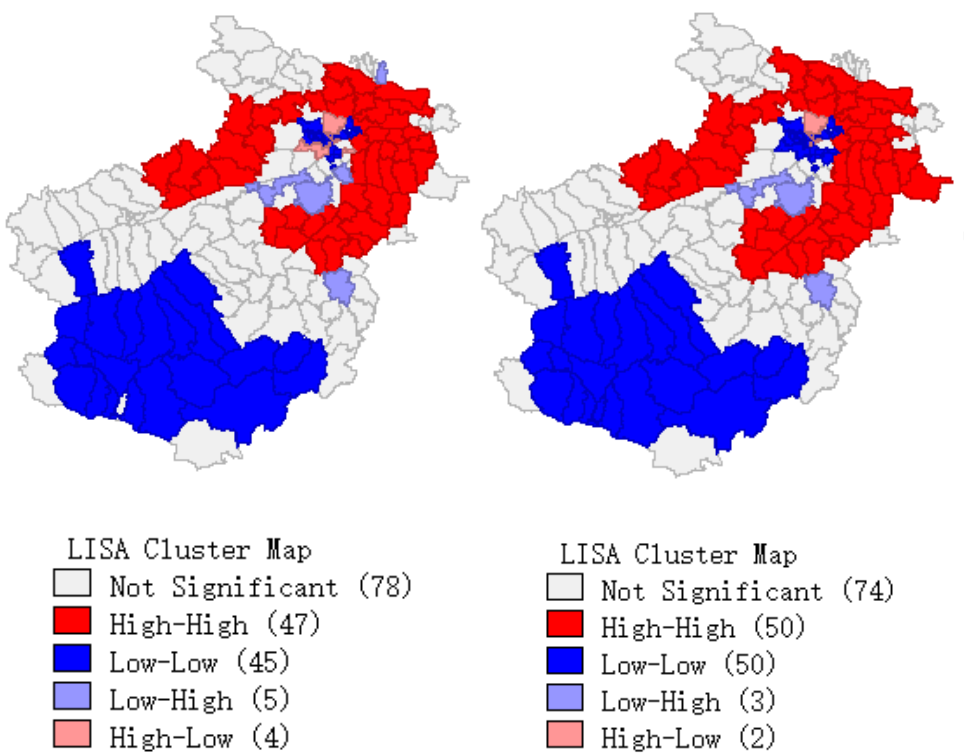

(a) 2009

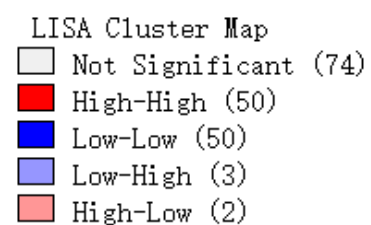

(b) 2014
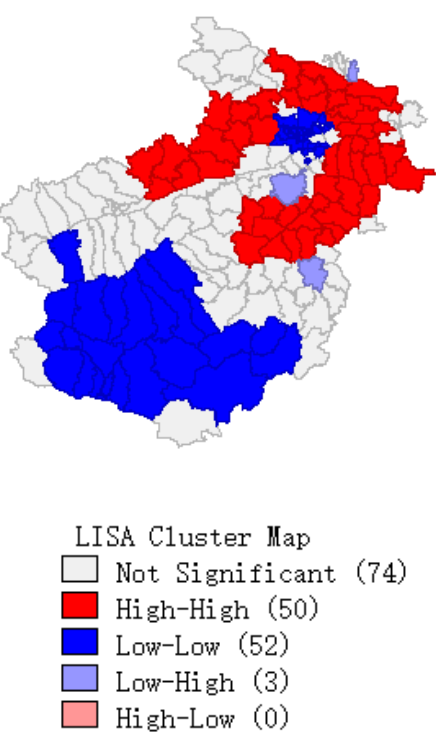

(c) 2019

Fig. 6. LISA Map of Cultivated Land Holdings in Luoyang City

The result shows that there is a dynamic balance in the amount of cultivated land holdings in Luoyang City between 2009 and 2019 and, overall, the distribution of the various types of clusters is basically consistent. Of these, approximately $26.25 \%$ of the total number of towns have a high-high type of cultivated land holdings, most of these being clustered in the northern and eastern parts of Luoyang City, and showing a distribution around the Luoyang City area. 
It can be observed from Fig. 6 that the overall change in townships of the high type is not obvious, with only the spatial autocorrelation of individual townships having changed in 2009-2014, cultivated land in the border area between the counties of Songxian and Yichuan has been increasing. No significant change from 2014 to 2019.

Depending on the terrain, the level of modernization and other factors, most of the towns with a low-low type of cultivated land holdings in Luoyang City are clustered in the southwestern mountains and in the urban areas. The number of towns and villages of low-low type has been on an increasing trend from 2009 to 2019, increasing from 25\% to 29\% of the total. From 2009 to 2014, the vicinity of the municipality changed from the not significant type or high-low type to the low-low type, indicating that the urban area was expanding at its periphery during this period, occupying more and more cultivated land.

The low-high type indicates local spatial variation within an area, mainly characterized by towns with a high quantity of cultivated land holdings surrounding towns with a low quantity. Fig. 6 illustrates that the number of towns and villages of this type is small and decreasing, from $3 \%$ in 2009 to $1.6 \%$ in 2019 . The theory of spatial polarization states that areas of high value surrounded by areas of low value will eventually be assimilated into the areas of low value. This means that the number of towns with high-low types will show a decreasing trend, year by year, due to spatial polarization. The characteristics of the low-low type are the opposite of the low-high type, in that their own high cultivated land holdings are surrounded by low cultivated land holdings. This type is only concentrated in the Luoyang City area, included the Xujaying Street Office and the Hongshan Street Office, both of which are located at a junction between the urban area and the surrounding counties, and both having a clear advantage over the urban area in terms of cultivated land quantity.

\subsection{Spatial Regression Model Analysis}

\subsubsection{Driving Factor Analysis}

The geographical environment often determines the size and quality of cultivated land within a region, while the increase, decrease and transfer of cultivated land is closely related to socioeconomic and cultural development and the level of urbanization. Therefore, the spatial pattern of cultivated land holdings can be influenced by a number of factors simultaneously. When analyzing the drivers of cultivated land shifts within regions, however, traditional statistical methods rely on the independent and evenly-distributed nature of the data over the study area, which is often not the case in reality. Due to spatial interactions, the spatial distribution of geographic data rarely exhibits complete spatial randomness, but is often interconnected, which defies the requirement that observed data be independent of each other, making spatial autocorrelation an important issue.

The strong spatial autocorrelation of cultivated land holdings in Luoyang City has been discussed above, so this nature of the data must be taken into account when studying the factors influencing the evolution of cultivated land. For this work, a binary global spatial autocorrelation was calculated using the Geoda tool with the 2009, 2014 and 2019 cultivated land holdings as the dependent variables, $\mathrm{y}$, and the corresponding elevation, slope, resident population and industrial output as the independent variables, x. The results are shown in Fig. 7, and the average holdings of cultivated land over the 10-year period 2009-2019 was calculated with each of the four driving factors. The holdings were subjected to a local spatial correlation analysis to obtain a LISA cluster diagram, as shown in Fig. 8, as a measure of the way in which the different influencing factors interact with the cultivated land holdings. 

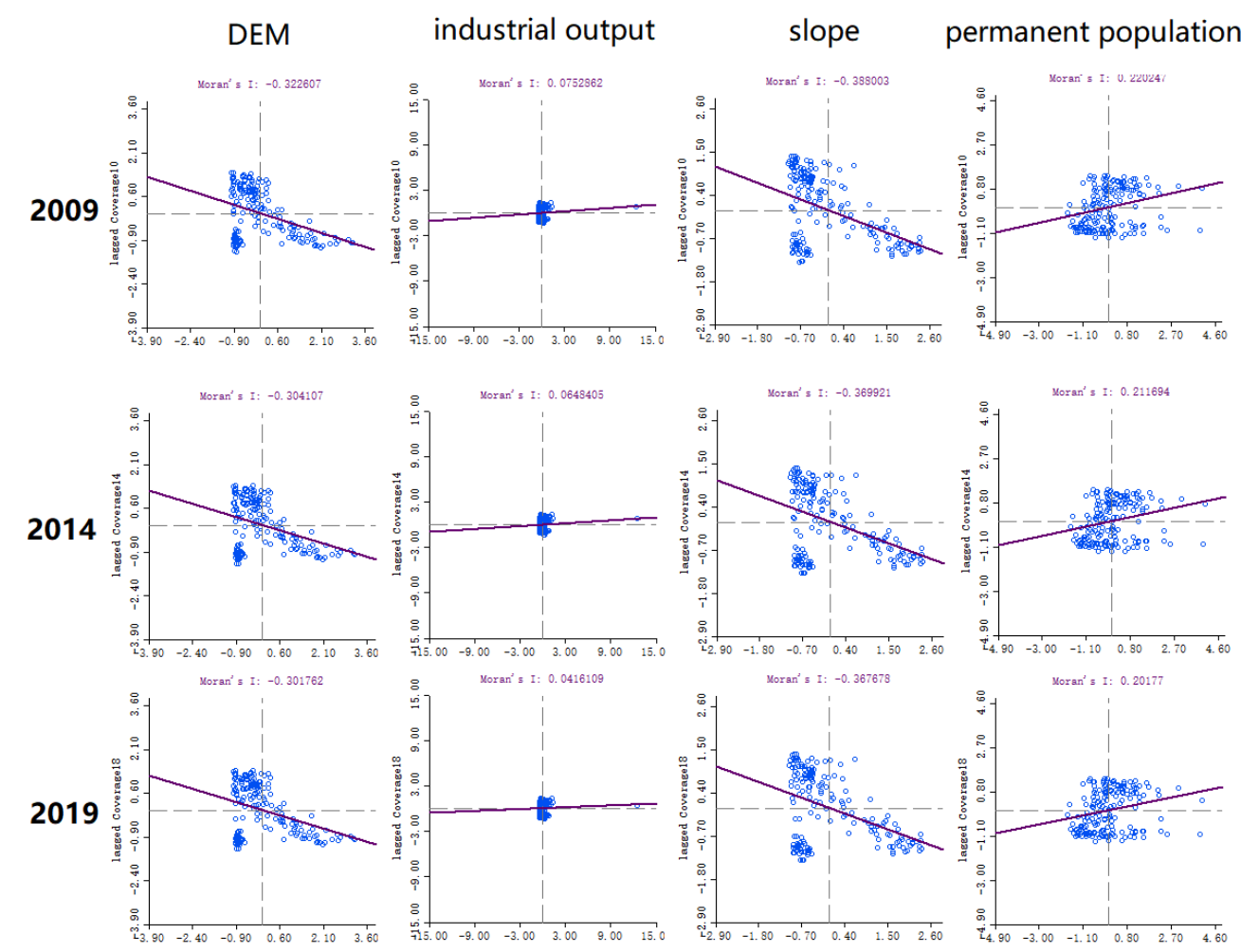

Fig. 7. Results of the Bivariate Spatial Autocorrelation
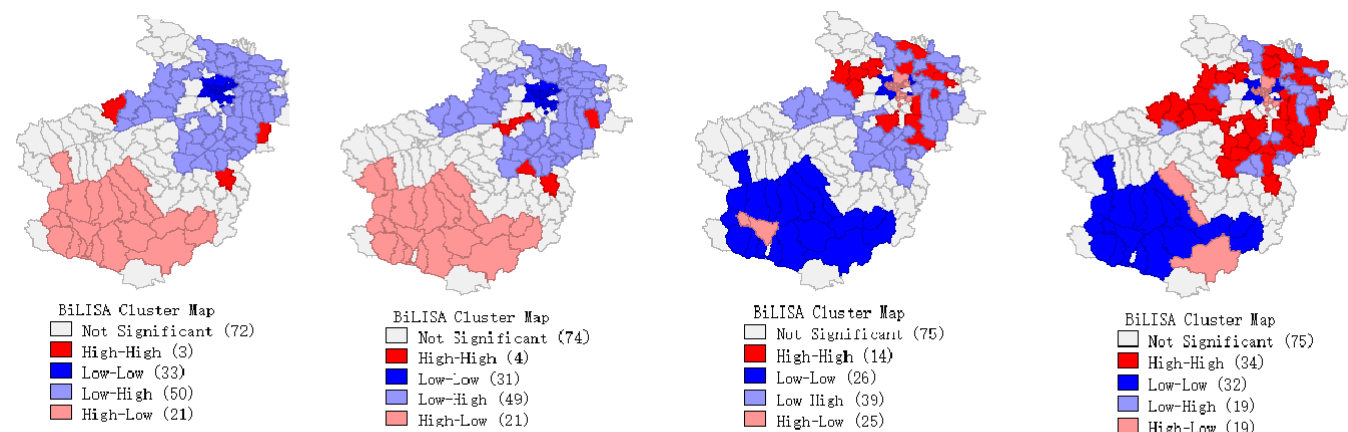

(a) DEM

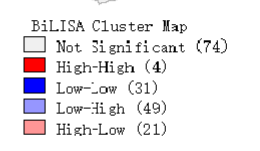

(b) Slope

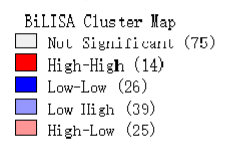

(c) Industrial Output

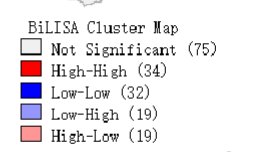

(d) Permanent Population

Fig. 8. LISA Maps of the Bivariate Local Spatial Autocorrelation

\subsubsection{Classical Linear Regression Analysis}

Linear regression models are used to describe the relationship between a dependent variable, $\mathrm{Y}$, and independent variables, $\mathrm{X} 1, \ldots ., \mathrm{Xn}$. Classical linear regression analysis is based on the method of ordinary least squares (OLS), and is a necessary step before spatial autoregression analysis can be carried out. In the results of this model, the regression coefficients indicate the extent to which the dependent variable is affected by changes in this particular autovariate, if all other conditions hold constant. Both t-statistics and p-values are used to test the significance of the effect of the autovariate on the dependent variable. A queen adjacency matrix was created in Geoda, followed by the calculation of the OLS regression model, the results of which are shown in Table 3. 
Table 3. OLS Model of Cultivated Land Holdings Quantity in Luoyang City

\begin{tabular}{|ccccc|}
\hline Variable & Coefficient & Std.Error & t-Statistics & p-value \\
\hline Constant & 0.540218 & 0.0575307 & 9.39007 & $<0.0001$ \\
\hline DEM & 0.000577309 & 0.000141622 & 4.07641 & 0.12702 \\
\hline Slope & -0.0459957 & 0.00756 & -6.08408 & $<0.0001$ \\
\hline permanent population & $1.67492 \mathrm{e}-007$ & $9.16594 \mathrm{e}-007$ & 0.182733 & 0.58522 \\
\hline industrial output & $-1.20097 \mathrm{e}-008$ & $1.43651 \mathrm{e}-008$ & -0.836102 & 0.40424 \\
\hline
\end{tabular}

Table 3 shows that the coefficients for the influencing factor elevation are positive, and the coefficients for the influencing factors slope, resident population and gross industrial output are negative, indicating that there is a positive correlation between cultivated land holdings and elevation, with a negative correlation between slope, resident population and gross industrial output. Of all these influencing factors, only slope passed the $1 \%$ significance test, however, with the coefficient showing that, for every $1 \%$ increase in slope, there is a $0.038 \%$ decrease in the amount of cultivated land holdings. In addition, the OLS model results list the parameters used to select which spatial autoregressive model is more consistent with the objective facts. As can be seen from Table 4, the residual Moran's I for the classical linear regression model was 0.159 and it passed the significance test, indicating that the residuals are spatially autocorrelated and that the introduction of a spatial autoregressive model is necessary.

Table 4. Spatial Correlation Test Results

\begin{tabular}{|cccc|}
\hline TEST & MI/DF & VALUE & PROB \\
\hline Moran's I(error) & 0.159 & 3.1076 & 0.00189 \\
\hline Lagrange Multiplier(lag) & 1 & 13.2549 & 0.00027 \\
\hline Robust LM(lag) & 1 & 6.3343 & 0.01184 \\
\hline Lagrange Multiplier(error) & 1 & 6.9736 & 0.00827 \\
\hline Robust LM(error) & 1 & 0.053 & 0.81791 \\
\hline
\end{tabular}

\subsubsection{Spatial Autoregressive Model Analysis}

Traditional classical linear regression models assume, in advance, that there is no spatial autocorrelation between study data. Spatial autoregression models correct this by incorporating spatial dependencies into the regression equation, which compensates for the shortcomings of classical measures when it comes to statistical spatial data. Therefore, herein, the factors influencing cultivated land holdings in Luoyang City were analyzed, using the 2014 Luoyang township cultivated land holdings as the dependent variable, and elevation, slope, resident population and industrial output as covariates, and the fit of the two models was compared. 
Table 5. SLM Model of Cultivated Land Holdings Quantity in Luoyang City

\begin{tabular}{|ccccc|}
\hline Variable & Coefficient & Std.Error & t-Statistics & p-value \\
\hline Lag coverage & 0.757795 & 0.0475766 & 15.9279 & 0.0003 \\
\hline Constant & 0.20559 & 0.0423458 & 4.85503 & $<0.0001$ \\
\hline DEM & 0.000361937 & $8.72628 \mathrm{e}-005$ & 4.14767 & $<0.0001$ \\
\hline Slope & -0.0251521 & 0.00483055 & -5.20689 & $<0.0001$ \\
\hline permanent population & $-5.06056 \mathrm{e}-007$ & $5.5656 \mathrm{e}-007$ & -0.909256 & 0.36322 \\
\hline industrial output & $-8.06186 \mathrm{e}-009$ & $8.7236 \mathrm{e}-009$ & -0.924144 & 0.35541 \\
\hline
\end{tabular}

The regression results of the SLM model based on the Geoda platform calculations are shown in Table 5. The regression coefficients and significance calculations show that slope and elevation have a significant effect on the amount of cultivated land holdings, with a pvalue of less than 0.01 , passing the $1 \%$ significance test. The effect of elevation on the dependent variable was also significant, with a p-value $<0.05$, indicating that it passed the $5 \%$ significance test. The remaining independent variable, resident population, is not significant for cultivated land holdings. The coefficient of slope is negative, indicating that the dependent variable cultivated land holdings decreased as slope increased in the study area. The absolute value of the regression coefficients indicates that slope had the greatest impact on cropland, in that, for every $1^{\circ}$ increase in slope, the amount of cropland holdings decreased by $0.032 \%$ in 2014, and that areas with excessive slopes are unsuitable for cultivation as cropland.

For every 10,000 RMB increase in industrial output value, the amount of cultivated land holdings decreased by $8.7236 \mathrm{e}-009$ percentage points in 2014 . The impact of industrial output value reflects the occupation of cultivated land by land used in the process of industrial development on the side, and the balance between occupation of and compensation for cultivated land will need special attention in the future protection of cultivated land. The regression coefficient for elevation is positive for each of the influencing factors, indicating a positive effect of elevation on cultivated land holdings, with the amount of cultivated land holdings increasing by $0.00036 \%$ for every 1 -m increase in land elevation in 2014 .

Table 6. SEM Model of Cultivated Land Holdings Quantity in Luoyang City

\begin{tabular}{|ccccc|}
\hline Variable & Coefficient & Std.Error & t-Statistics & p-value \\
\hline CONSTANT & 0.547977 & 0.0665825 & 8.23004 & $<0.0001$ \\
\hline DEM & 0.000331962 & 0.000131954 & 2.51574 & 0.01188 \\
\hline slope & -0.0343278 & 0.00571905 & -6.00236 & $<0.0001$ \\
\hline permanent population & $-9.04 \mathrm{E}-07$ & $5.35 \mathrm{E}-07$ & -1.68828 & 0.09136 \\
\hline industrial output & $-1.51 \mathrm{E}-08$ & $8.04 \mathrm{E}-09$ & -1.87316 & 0.06105 \\
\hline Lambda & 0.80694 & 0.0430819 & 18.7304 & $<0.0001$ \\
\hline
\end{tabular}


Table 6 shows that the coefficients for the influencing factor elevation are positive, while the coefficients for the influencing factors slope, resident population and total industrial output are negative, indicating that there is a positive correlation between cultivated land tenure and elevation, and a negative correlation between slope, resident population and total industrial output. Of all the influencing factors, however, only slope passed the $1 \%$ significance test, with the coefficients showing that, for every $1 \%$ increase in slope, there is a $0.034 \%$ decrease in the amount of cultivated land holdings.

Scholar Anselin [27] proposed a criterion for choosing a spatial autoregressive model. In the spatial correlation test, the significance of the $\mathrm{LM}(\mathrm{lag})$ and the $\mathrm{LM}$ (error) is first discriminated and, if either is significant, the corresponding spatial autoregressive model is used. If both are significant, comparison of the robust LM(lag) and robust LM(error) values continues. From Table 4, it can be seen that the robust $\mathrm{LM}(\mathrm{lag})$ is more significant than the robust $\mathrm{LM}$ (error) in this case, so the spatial lag model is more in line with the objective facts.

At the same time, the actual values of the dependent variable and the predicted values of the individual regression models were used to generate fit curves, as shown in Fig. 9. These show that the spatial lag model prediction (LAG_PREDIC) has a better fit to the actual values of cultivated land tenure (Coverage14).

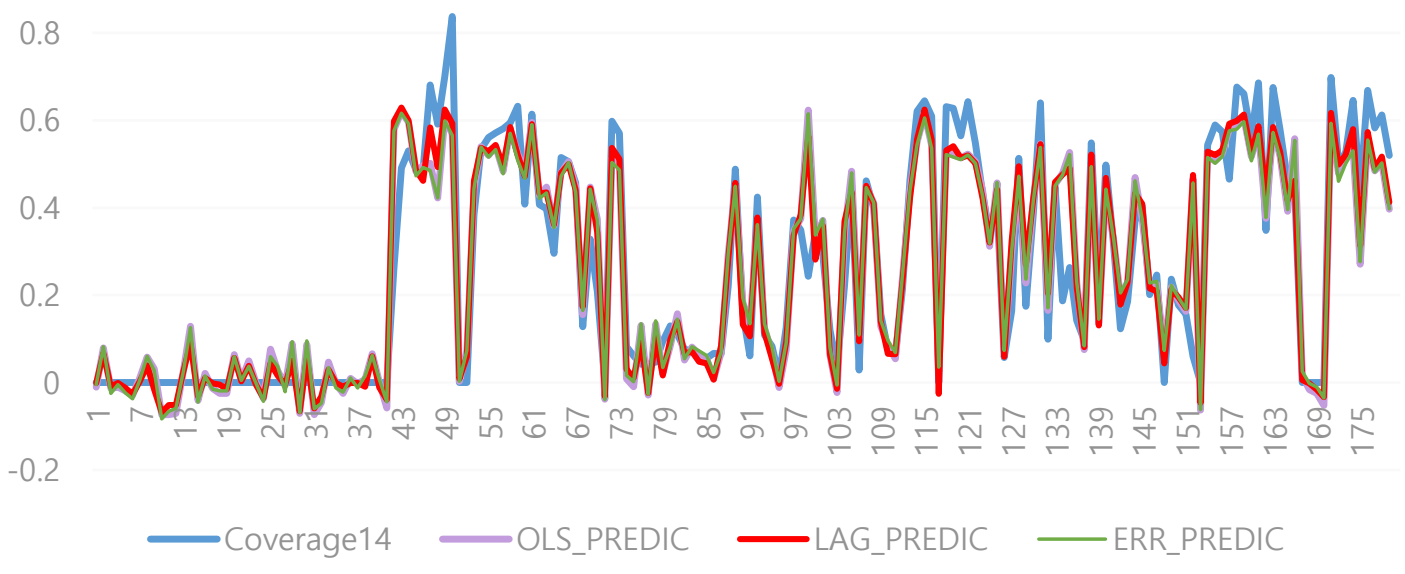

Fig. 9. Model Prediction Value Fitting Curve

\section{Discussion and Conclusions}

In this study, we analyzed the evolution of the spatial pattern of cultivated land at the township scale with the help of a spatial autocorrelation analysis model, based on the spatial and temporal data of cultivated land use in Luoyang City in 2009, 2014 and 2019. In addition, classical factors, such as elevation, slope, population and industrial output value, were chosen as examples to analyze the driving mechanism of the spatial changes in cultivated land in Luoyang City. The findings are as follows:

(1) In terms of the transfer of cultivated land from the countryside, the main sources of cultivated land transferred out were urban(73.27\%) industrial and $\operatorname{mining}(8.21 \%)$, and transport land(14.35\%), while the main sources of land transferred in were grassland(44.41\%), water and water conservancy facility $(18.01 \%)$, and forest $(10.98 \%)$.

(2) Calculation of the global Moran I index values(Moran's I 0.7134) showed that there 
was a strong spatial correlation between the amount of cultivated land holdings in Luoyang City. From the results of the local spatial autocorrelation, high-high type concentrated in the northeastern border areas of Luoyang City, and with a minor expansion during the period 2009-2019. The low-low type of townships were concentrated in the south of Luoyang City, and were heavily influenced by topography and urbanization. The expansion of this type of area during the study period mainly occurred in the Luoyang City area, mostly influenced by spatial polarization and assimilation by the lower values in the high-low areas.

(3) Analysis of the 2014 spatial autoregressive model revealed that, slope and industrial output all having a significant effect on cultivated land holdings. The absolute values of the regression coefficients indicated the magnitude of the influence of the different factors on the amount of cultivated land holdings as being slope > elevation > gross industrial output. Whereas elevation had a positive effect, slope and industrial output had a negative effect.

\section{Acknowledgement}

This research was funded by the Open Fund Project of the Key Laboratory of Urban Land Resources Monitoring and Simulation of the Ministry of Natural Resources, grant number KF2019-04-038. National Natural Science Foundation of China, grant number 41771438. Open Fund Project of the Key Laboratory for Synergistic Prevention of Water and Soil Environmental Pollution, grant number KLSPWSEP-A01. Beijing Social Science Foundation Major project 'Research on building an ecological civilization system', grant number 19ZDA03.

\section{References}

[1] X. Z. Deng, J. K. Huang, R. Scott, J. Zhang, and Z. Li, "Impact of urbanization on cultivated land changes in China," Land Use Policy, vol. 45, pp. 1-7, 2015. Article (CrossRef Link)

[2] J. F. Chen, S. Q. Wei, K. T. Chang, and B. W. Tsai, "A comparative case study of cultivated land changes in Fujian and Taiwan," Land Use Policy, vol. 24, no. 2, pp. 386-395, 2006.

Article (CrossRef Link)

[3] Z. H. Lai, M. Q. Chen, and T. J. Liu, "Changes in and prospects for cultivated land use since the reform and opening up in China," Land Use Policy, vol. 97, 2020. Article (CrossRef Link)

[4] S. Q. Qu, Y. F. Liu, C. H. Yin, and Z. Y. Zhang, "Spatial pattern of cultivated land change in Fujian Province from 1990 to 2015," Chinese Journal of Eco-Agriculture, vol. 28, no. 4, pp. 587-598, Apr. 2020. Article (CrossRef Link)

[5] W. M. Cai, T. Xiao, F. Y. Bi, and Y. Z. Shi, "Analysis of spatial Distribution characteristics of cultivated land based on kernel density estimation in Metropolis - A case study in Tianjin," Chinese Journal of Agricultural Resources and Regional Planning, vol. 40, no. 01, pp. 152-160, 2019. Article (CrossRef Link)

[6] Y. Yang, X. Y. Ma, and C. Y. He, "The loss process of cultivated land based on GlobeLand 30: A case study of Bohai Rim," China Land Sciences, vol. 30, no. 7, pp. 72-79, 2016.

Article (CrossRef Link)

[7] Y. N. Zeng, W. P. Jin, H. M. Wang, and L. Tan, "Analysis and evaluation of cultivated land decrease in eastern part of Qinghai Plateau," Transactions of the Chinese Society of Agricultural Engineering, vol. 29, no. 21, pp. 214-222, 2013. Article (CrossRef Link) 
[8] X. Q. Song, Z. Ouyang, Y. S. Li, and F. D. Li, "Cultivated land use change in China, 1999-2007: Policy development perspectives,” Journal of Geographical Sciences, vol. 22, no. 06, pp. 10611078, 2012. Article (CrossRef Link)

[9] D. L. Zhu, "Strictly regulate and supplement the national planning of cultivated land," China Land, no.3, pp. 6-8, 2017. Article (CrossRef Link)

[10] Y. Y. Shi , X. Lyu, X. J. Huang, M. Yu, “Arable land use transitions and its response of ecosystem services value change in Jiangsu coastal areas," Journal of Natural Resources, vol. 32, no. 6, pp. 961-976, 2017. Article (CrossRef Link)

[11] X. M. Tang, Y. C. Pan, Y. Liu, "Evaluation and spatio-temporal analysis of ecological value of cultivated land in Beijing," Chinese Journal of Agricultural Resources and Regional Planning, vol. 39, no. 3, pp. 132-140, 2018. Article (CrossRef Link)

[12] G. Yang, L. Q. Xue, X. L. He, C. Wang, and A. Long, "Change in land use and evapotranspiration in the Manas River Basin, China with long-term water-saving measures," Scientific Reports, vol. 17874, 2017. Article (CrossRef Link)

[13] S. Xu, "Temporal and Spatial Characteristics of the Change of Cultivated Land Resources in the Black Soil Region of Heilongjiang Province (China),” Sustainability, vol. 11, no. 1, 2018. Article (CrossRef Link)

[14] S. Wang, S. R. Stephenson, and S. Qu "Modeling spatially non-stationary land use/cover change in the lower Connecticut River Basin by combining geographically weighted logistic regression and the CA-Markov model," International Journal of Geographical Information Science, vol. 33, no. 7, pp. 1313-1334, 2019. Article (CrossRef Link)

[15] H. Jin, A. M. Yang, X. X. Xia, L. Zhu, and Q. Zhang, "Simulation of land use change at different time spans based on CA-Markov model," Arid Land Geography, vol. 42, no. 6, pp. 1415-1426, 2019. Article (CrossRef Link)

[16] Z. Y. Yao, L. J. Zhang, S. H. Tang, Z. Li, and T. Hao, "The basic characteristics and spatial patterns of global cultivated land change since the 1980s," Journal of Geographical Sciences, vol. 27, no. 7, pp. 771-785, 2017. Article (CrossRef Link)

[17] V. Ranga, J. Poesen, A. Van Rompaey, and P. Pani, "Detection and analysis of badlands dynamics in the Chambal River Valley (India), during the last 40 (1971-2010) years," Environmental Earth Sciences, vol. 75, no. 183, 2016. Article (CrossRef Link)

[18] A. D. Cliff and J. K. Ord, Spatial Autocorrelation, London: Pion, 1973.

[19] L. Zhu, A. M. Yang, X. X. Xia, and H. Q. Wu, "Spatial distribution pattern and change characteristics analysis of cultivated land in the Manas River Basin from 1975 to 2015," Chinese Journal of Eco-Agriculture, vol. 28, no. 6, pp. 887-899, 2020. Article (CrossRef Link)

[20] J. G. Gao and R. Huang, "Protection Zoning of Cultivated Land Based on Cultivated Land Quality Index and Spatial Autocorrelation on Southern Area of Jiangsu Province," Research of Soil and Water Conservation, vol. 26, no. 03, pp. 213-218, 2019. Article (CrossRef Link)

[21] H. Zhang, X. M. Zhao, Z. C. Ouyang, X. Guo, W. Li, Y. Ye, C. Huang, and X. Wang, "Multi-scale spatial autocorrelation analysis of cultivated land quality in China's southern hillside areas: A case study of Lichuan County, Jiangxi Province," Chinese Journal of Eco-Agriculture, vol. 26, no. 02, pp. 263-273, 2018. Article (CrossRef Link)

[22] A. O. Arowolo, X. Z. Deng, "Land use/land cover change and statistical modelling of cultivated land change drivers in Nigeria," Regional Environmental Change, vol. 18, no. 1, pp. 247-259, 2018. Article (CrossRef Link)

[23] P. Ren, T. Wu, and J. M. Zhou, "Analysis of spatial distribution pattern and evolutionary characteristics of cultivated lands based on spatial autocorrelation model and GIS platform-A case study of Longquanyi District, Chengdu, China," Chinese Journal of Eco-Agriculture, vol. 24, no. 3, pp. 325-334, 2016. Article (CrossRef Link)

[24] C. K. Sun, J. L. Xu, D. Yu, W. Zhou, J. P. Wang, and Z. B. Liang, "Spatial distribution of cultivated land quality at different scales in Chongyi County," Chinese Journal of Eco-Agriculture, vol. 27, no. 4, pp. 601-612, 2019. Article (CrossRef Link) 
[25] W. M. Cheng, X. Y. Ga, T. Ma, X. Xu, Y. Chen, and C. Zhou, "Spatial-temporal distribution of cropland in China based on geomorphologic regionalization during 1990-2015," Acta Geographica Sinica, vol. 73, no. 9, pp. 1613-1629, 2018. Article (CrossRef Link)

[26] Z. H. Chao, P. D. Zhang, and X. F. Wang, "Impacts of urbanization on the net primary productivity and cultivated land change in Shandong province, China," Journal of the Indian Society of Remote Sensing, vol. 46, no. 5, pp. 809-819, 2018. Article (CrossRef Link)

[27] L. Anselin, Spatial Econometrics: Methods and Models, Dordrecht, Netherlands: Kluwer Academic Publishers, 1988.

[28] GB/T 21010-2007, Classification of land use status. Article (CrossRef Link)

[29] C. Zhao, L. Wang, Q. X. Zhang, and G. F. Zhang, "Study on land-use transition matrix and spatial changes of Buha River Basin,” Water Resources and Hydropower Engineering, vol. 47, no. 05, pp. 6-11, 2016. Article (CrossRef Link)

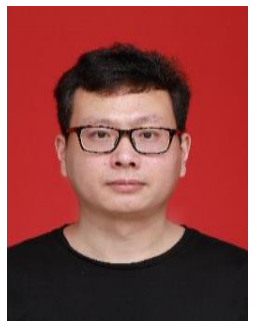

Hua Wang received the Ph.D. degree from Wuhan University in 2013. He is currently a research staff of Zhengzhou University of Light Industry (ZZULI), Henan, China. His current research interests include applications of artificial intelligence, spatial optimization decision, GIS

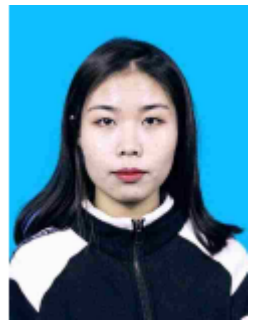

Yuxin Zhu is currently working toward a master's degree with the School of Computer and Communication Engineering, Zhengzhou University of Light Industry, (ZZULI), Henan, China. Her current research interests include spatial optimization decision, GIS, applications of artificial intelligence.

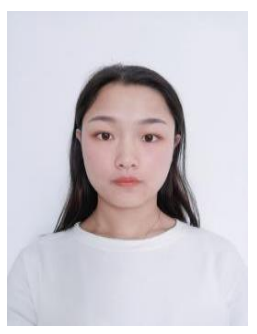

Mengyu Wang is currently studying Data Science and Big Data Technology at Zhengzhou University of Light Industry (ZZULI), Henan, China. Her current research interests include spatial optimization decision, GIS, applications of artificial intelligence. 


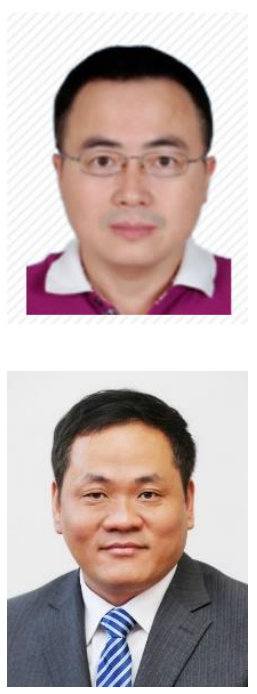

Xueye Chen graduated from Wuhan University with a Master's degree and is currently the Director of Shenzhen Digital City Engineering Research Centre. He is mainly engaged in the application development, research and management of GIS, remote sensing, e-government, digital city and other technologies.

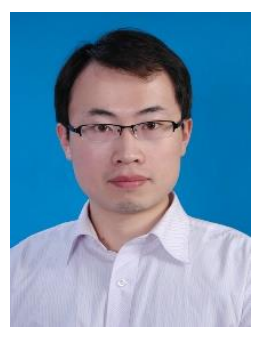

Jiqiang Niu received the Ph.D. degree from Wuhan University in 2010. He is a Professor of Xinyang Normal University, Henan, China. His current research interests include spatial data mining, spatial data uncertainty.

Yang Zhang received the Ph.D. degree from Wuhan University in 2012. He is currently a research staff of Capital University of Economics and Business (CUEB), Beijing, China. His current research interests include spatial optimization, sustainable development, GIS. 